УДК 691.32-047.38

\author{
Н. М. Битько, к.т.н., доиент, \\ e-mail: bitkonm@ukr.net \\ О. В. Кузнецова, стариий преподаватель, \\ e-mail: kuznes-68@ukr.net \\ В. В. Бойко, стариий преподаватель \\ e-mail: boykin.valentina@gmail.com \\ Черкасский государственный технологический университет \\ б-р Шевченко, 460, г. Черкассы, 18006, Украина \section{НАПРЯЖЕННО-ДЕФОРМИРОВАННОГО СОСТОЯНИЯ БЕТОНОВ ПРИ ДЛИТЕЛЬНОМ ЦЕНТРАЛЬНОМ СЖАТИИ} \\ ТЕОРЕТИЧЕСКИЕ ИССЛЕДОВАНИЯ
}

Изложены результаты теоретических исследований напряженно-деформированного состояния бетонов при длительном иентральном сжатии на основе его структурной теории. Проведен анализ определения напряженно-деформированного состояния, исходя из двух наиболее приемлемых структурных схем бетона. Приводятся положительные и отрицательные моменты использования этих схем. На основе анализа выбраны две схемы для определения упругопластических характеристик бетона при длительном воздействии нагрузки, исходя из реологических свойств составляюших. Для схемы шахматного расположения заполнителя в иементной матрице, исходя из решений равновесия и совместности деформаций, получены их теоретические значения. Проведено сравнение полученных теоретических значений характеристик бетона и раствора при длительном действии нагрузки с данными, полученныли экспериментально. Результаты сравнения опытных и теоретических значений свидетельствуют о возможности применения этих зависимостей для определения упругопластических характеристик бетона при длительном действии нагрузки, исходя из состава его компонентов.

Ключевые слова: модуль упругости, бетон, раствор, структурная схема, составляющие бетона, заполнитель, цементный камень.

Введение. В настоящее время бетон является основным строительным материалом. Однако его прочностные и деформативные характеристики как при кратковременном, так и длительном приложении нагрузки, которые базируются на прочностных и деформативных характеристиках его составляющих, изучены недостаточно. По этой причине при решении многих задач теории бетона и железобетона исходят из феноменологических зависимостей, взятых непосредственно с результатов испытаний.

Однако уже имеется некоторая тенденция к использованию не феноменологии, а сущности явления и разработке структурной теории бетона. Расчётные формулы при этом основываются на прочностных и упругопластических характеристиках составляющих бетона, их количественном соотношении и взаиморасположении в единице объема.

Постановка проблемы. Бетон является конгломератом и имеет твердые, жидкие и газообразные включения. Взаиморасположе- ние составляющих в единице бетонного элемента осуществляется при помощи идеализированных структурных схем бетона. Действительная структурная схема бетона сложная и не поддаётся статистической оценке. Цементный камень при этом рассматривается как матрица, а заполнители - как включения. Но цементный камень и заполнитель имеют различные физико-механические свойства, поэтому упругопластические характеристики бетона должны определяться через реологические свойства составляющих, их количественное соотношение и взаиморасположение. Решение этой задачи является весьма актуальным.

Анализ результатов исследований. По этому вопросу имеется незначительное количество исследований. Так, авторы [1-2] дают определение модуля упругости бетона по двум идеализированным структурным схемам (рис. 1, схемы 1,2).

Несколько иные, при кратковременном центральном сжатии, зависимости для опре- 
деления модуля упругости бетона рассмотрены в [3-12]. Все они касаются определения модуля упругости и упругопластических характеристик бетона при кратковременном центральном сжатии. Что же касается оценки его деформативности по идеализированным схемам при длительном сжатии нагрузкой различной интенсивности, то ни один из вышеуказанных авторов таковой не дает.

Цель работы - разработка на основе идеализированных структурных схем бетона аналитических зависимостей для определения его напряженно-деформированного состояния при длительном центральном сжатии нагрузкой различной интенсивности, исходя из реологических свойств составляющих.

Изложение основного материала. Оценка напряженно-деформированного состояния бетонов при кратковременном сжатии по их составу и реологическим свойствам составляющих приведена на идеализированных структурных схемах 1, 2 (рис. 1)[2].

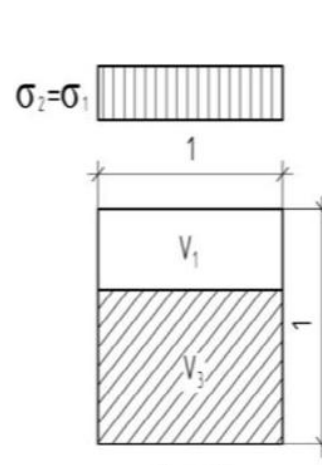

[xема 1

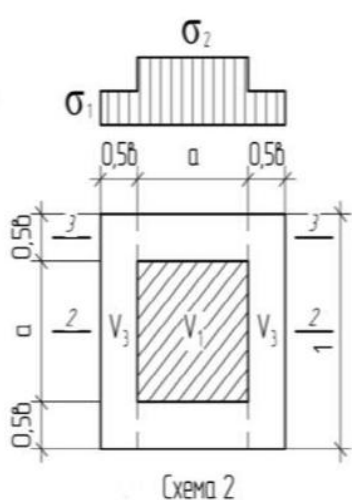

[xema 2
Рис. 1. Идеализированные структурные схемы

Источник: [2].

Оценку напряженно-деформированного состояния бетонов при длительном центральном сжатии производим по схемам 1 и 2 [2] как наиболее точно отражающим работу бетона при кратковременном загружении.

Дополнительные предпосылки:

1. Нелинейная зависимость между напряжениями и характеристикой ползучести бетонов. 2. Линейная зависимость между секущим модулем полных деформаций (с учетом деформаций ползучести) $E_{1, \eta, t \tau}$ и начальным уровнем длительных напряжений $\eta_{\tau}$ в фиксированный момент времени $t-\tau$ для цементного камня (раствора). Экспериментальностатистическое обоснование этих предпосылок приведено в [2].
В процессе длительных испытаний по схеме 1 (рис. 1) напряжения в цементном камне $\sigma_{1, \eta, t, \tau}$ и заполнителе $\sigma_{3, \eta, t, \tau}$ в момент времени $(t-\tau)$ одинаковы и равняются напряжениям в бетоне:

$$
\sigma_{1, \eta, t, \tau}=\sigma_{3, \eta, t, \tau}=\sigma_{c, \eta, t, \tau}
$$

В цементном камне с течением времени нарастают деформации ползучести. Заполнитель работает упруго. Секущий модуль полных деформаций бетона $E_{1 c, \eta, t, \tau}$ в любой момент времени $(t-\tau)$ определяется по зависимости

$$
E_{c, \eta, t, \tau}^{\prime}=\frac{I}{\frac{V_{1}}{E_{1, \eta, t, \tau}^{\prime}}+\frac{V_{3}}{E_{3}}},
$$

где

$$
E_{1, \eta, t, \tau}^{\prime}=\frac{E_{1, \eta, \tau}^{\prime}}{1+\varphi_{1, \eta, t, \tau}}
$$

В формулах (1)-(2):

$V_{1}$ - объем цементного камня;

$V_{3}$ - объем заполнителя;

$E_{3}$ - модуль упругости заполнителя;

$E_{1, \eta, t, \tau}^{\prime}$ - секущий модуль деформаций цементного камня при кратковременном загружении при уровне напряжений $\eta_{\tau}$;

$\sigma_{1, \eta, t, \tau}$ - характеристика ползучести цементного камня в момент времени $(t-\tau)$ при начальном уровне длительного обжатия $\eta_{\tau}$.

В работе [13] получены формулы для теоретического определения внутреннего напряженно-деформированного состояния бетона по схеме 2 (рис. 1). В этой работе не учтены нелинейная зависимость характеристики ползучести бетонов от уровня действовавших напряжений и линейная зависимость «секущего модуля полных деформаций - напряжения». Сравнение полученных автором [13] формул производилось только для одного уровня обжатия $\sigma_{\eta}=8$ МПа и одной продолжительности действия сжимающей загрузки $(t-\tau)=80 \mathrm{c}$. В работе принято допущение независимости характеристики ползучести от уровня сжимающих напряжений, что не подтвердилось в опытах авторов настоящей работы.

В процессе длительных испытаний по схеме 2 напряжения в цементном камне в го- 
ризонтальной прослойке элемента II увеличиваются, а в вертикальном элементе I уменьшаются. Как в одном, так и в другом случаях зависимость «секущий модуль полных деформаций - напряжение» $\left(E_{1, \eta, t, \tau}^{\prime}-\sigma_{1, \tau}\right)$ является линейной корреляционной. Внутреннее напряженное состояние $\sigma_{1, \tau}$ и $\sigma_{2}, \tau=\sigma_{3}$ определяется сечением 2-2 по схеме с вертикальными прослойками элемента I.

Задача определения внутреннего напряженно-деформированного состояния решается двумя путями.

Предполагается полная обратимость деформаций ползучести цементного камня в процессе его разгрузки за счет перераспределения усилий между цементным камнем и заполнителем при постоянном сжимающем напряжении в бетоне $\sigma_{c, \tau}=\sigma_{c, t}$ в процессе длительной выдержки под нагрузкой. При этом суммарная деформация цементного камня при напряжении $\sigma_{1, \eta, t, \tau}<\sigma_{1, \eta, \tau}$ равна суммарной деформации этого же элемента при постоянном напряжении $\sigma_{1, \eta, t, \tau}=$ const. Иными словами, кривая разгрузки $\bar{\sigma}_{1, \eta, t, \tau}-\bar{\varepsilon}_{1, \eta, t, \tau}$ в процессе перераспределения усилий совпадает с кривой загрузки.

При такой предпосылке уравнение равновесия имеет вид:

$$
\sigma_{1, \eta, t, \tau} A_{1}+\sigma_{3, \eta, \eta, \tau} A_{3}=\sigma_{c, \eta, t, \tau} A_{3}
$$

а уравнения совместности деформаций составляющих бетона:

$$
\begin{aligned}
\varepsilon_{c, \eta, t, \tau}= & \varepsilon_{1, \eta, t, \tau}=\varepsilon_{3, \eta, t, \tau}=\frac{\sigma_{c, \eta, \tau}}{E_{c, \eta, 2, t, \tau}^{\prime}}= \\
= & \frac{\sigma_{1, \eta, t, \tau}}{E_{1, \eta, 2, t, \tau}^{\prime}}=\frac{\sigma_{3, \eta, t, \tau}}{E_{3}} .
\end{aligned}
$$

При этом используем опытнокорреляционную зависимость $E_{1, \eta, t, \tau}^{\prime}-\eta_{1, \tau}$ при длительном центральном сжатии постоянной нагрузкой различной интенсивности в сечении 2-2:

$$
E_{1, \eta, 2, t, \tau}^{\prime}=E_{1,0, t, \tau}\left(1-\lambda_{f c d 1, e, \tau} \frac{\sigma_{1, \eta, t, \tau}}{f c d_{1, \tau}}\right) .
$$

Секущий модуль деформаций бетона с учетом ползучести в этом случае имеет вид

$$
E_{c, \eta, 2, t, \tau}^{\prime}=A_{1} E_{1 \eta, 2, t, \tau}^{\prime}+F_{3} E_{3} .
$$

Подставив значение секущего модуля деформаций цементного камня с учетом ползучести в сечении 2-2 $E_{1, \eta, 2, t, \tau}$ в (6) и решив квадратное уравнение, определяем значение секущего модуля деформаций бетона с учетом ползучести для сечения 2-2:

$E_{c, \eta, 2, t, \tau}^{\prime}=0,5 B+\sqrt{(0,5 B)^{2}-C}$,

где $B=-\left[E_{0},{ }_{c, 2, t, \tau}-\lambda_{f c d} E_{0,1, t, \tau} \frac{\sigma_{c, \tau}}{f_{c d, 1, \tau}}\right]$;

$$
C=A_{3} E_{3} \lambda_{f_{c d, 1, t . \tau}} E_{0,1, t, \tau} .
$$

Значение секущего модуля деформаций цементного камня с учетом ползучести в сечении 2-2 определяется из (6):

$$
E_{1, \eta, 2, t, \tau}^{\prime}=\frac{E_{c, \eta, 2, t, \tau}^{\prime}-E_{3} A_{3}}{A_{1}} .
$$

В формулах (3)-(10):

$$
\begin{gathered}
E_{1,1, \tau}^{\prime}=E_{0,1, \tau}\left(1-\lambda_{f c d, 1, \tau} \frac{\sigma_{1, \eta, \tau}}{f_{c d, 1, \tau}}\right) ; \\
E_{0,1, t, \tau}=\frac{E_{0,1, \tau}}{1+\varphi_{0,1, t, \tau}} ; \\
E_{R 1, t, \tau}^{\prime}=\frac{E_{R, 1, \tau}^{\prime}}{1+\varphi_{R, 1, t, \tau}} ; \\
\lambda_{f c d_{1, t, \tau}}=1-\frac{E_{R, 1, t, \tau}^{\prime}}{E_{0,1, t, \tau}} ; \\
E_{0, c, \eta, 2, t, \tau}=\frac{A_{1} E_{0,1, \tau}}{1+\varphi_{0,1, t, \tau}}+A_{3} E_{3} .
\end{gathered}
$$

В формулах (11)-(15) значения $E_{1,0, \tau}$ и $E_{R, 1, \tau}^{\prime}$ определяются по (11) при напряжении $\sigma_{1, \eta, \tau}$, равном соответственно 0 и $f_{c d, 1, \tau}$. Значения $A_{1}$ и $A_{3}$ определяются по зависимостям, данным в [2]. Внутреннее напряженное состояние бетона по схеме 2 определяется сечением 2-2:

$$
\begin{gathered}
\sigma_{1, \eta, t, \tau}=\sigma_{c, \eta, \tau} \frac{E_{1, \eta, 2, t, \tau}^{\prime}}{E_{c, \eta, 2, t, \tau}^{\prime}}, \\
\sigma_{3, \eta, t, \tau}=\sigma_{2, \eta, t, \tau}=\frac{\sigma_{c, \eta, \tau}-A_{1} \sigma_{1, \eta, t, \tau}}{A_{3}} .
\end{gathered}
$$


Модуль полных деформаций идеализированной структурной схемы 2 оценивается по формуле

$$
E_{c, \eta, t, \tau}^{\prime}=A^{\prime} E_{I, 1, \eta, t, \tau}^{\prime}+\frac{A_{3}}{\frac{a}{E_{3}}+\frac{b}{E_{I I, 1, \eta, t, \tau}^{\prime}}},
$$

где $E_{1,1, \eta, t, \tau}^{\prime}$ - модуль полных деформаций цементного камня (раствора) в элементе I схемы 2:

$$
\begin{aligned}
& E_{1,1, \eta, t, \tau}=E_{1,0, \tau}\left[\frac{1-\eta_{, 1,1, t, \tau}}{1+\varphi_{0,1, t, \tau}}+\right. \\
& \left.+\frac{v_{f c d, 1, \tau} \eta_{I I, 1, t, \tau}}{1+\varphi_{R, 1, t, \tau}}\right] .
\end{aligned}
$$

$E^{\prime}{ }_{I I, 1, \eta, t, \tau}$ - модуль полных деформаций горизонтальной прослойки цементного камня (раствора) в комбинированном элементе II:

$$
\begin{aligned}
& E_{I I, 1, \eta, t, \tau}^{\prime}=E_{1,0, \tau}\left[\frac{1-\eta_{, I I, 1, t, \tau}}{1+\varphi_{0,1, t, \tau}}+\right. \\
& \left.+\frac{v_{f c d, 1, \tau} \eta_{I I, 1, t, \tau}}{1+\varphi_{R, 1, t, \tau}}\right] .
\end{aligned}
$$

В формулах (19)-(22):

$$
\begin{gathered}
\eta_{1,1, t, \tau}=\frac{\sigma_{1, \eta, t, \tau}}{f c d_{1, \tau}} ; \\
\eta_{I I, 1, t, \tau}=\frac{\sigma_{3, \eta, t, \tau}}{f c d_{1, \tau}} ; \\
v_{f c d, 1, \tau}=\frac{E_{R, 1, \tau}^{\prime}}{E_{0,1, \tau}} ;
\end{gathered}
$$

$\varphi_{0,1, t . \tau}$ и $\varphi_{R, 1, t . \tau}-$ начальное (при $\eta_{\tau}=0$ ) и предельное (при $\eta_{\tau}=1$ ) значения характеристик ползучести цементного камня (раствора) для любого фиксированного времени $(t-\tau)$.

Полные относительные деформации бетона (упругопластические и деформации ползучести) к фиксированному моменту времени $t-\tau$ при любом начальном уровне длительного обжатия $\eta_{\tau}=\sigma_{\tau} / f c d, \tau$ определяются по формуле

$$
\varepsilon_{c \eta, t, \tau}=\frac{\sigma_{c, \eta, \tau}}{E_{c \eta, t, \tau}^{\prime}}=\frac{\sigma_{c, \eta, t, \tau}}{E_{c, \eta, t, \tau}^{\prime}} .
$$

Во втором случае предполагается, что кривая $(\bar{\sigma}-\bar{\varepsilon})$ длительной разгрузки цементного камня принимается тождественной кривой загрузки этого же элемента в фиксированный отрезок времени $(t-\tau)$. Эта предпосылка тождественности кривой $(\sigma-\varepsilon)$ при длительной загрузке и разгрузке учитывает неполную обратимость нелинейных деформаций ползучести, в зависимости от начального уровня длительного обжатия $\eta_{\tau}$.

Расчетные формулы для этого случая не приводятся.

Как показало сравнение теоретических значений $\varepsilon_{\eta, t, \tau}$, полученных для идеализированной структурной схемы, то до начального уровня длительного обжатия $\eta_{\tau}=0,5$ различие между ними практически отсутствует, а после уровня $\eta_{\tau}=0,5$ различие достигает $4,8 \%$.

В табл. 1 и 3 приведены опытные и теоретические значения полных относительных деформаций по схеме 2 для первого случая и по схеме 1 для различных моментов времени $t-\tau$ и при различных начальных уровнях длительного обжатия $\eta \tau$ в системе «растворбетон» по результатам серии испытаний образцов тяжелых бетонов (ТБ-3).

В обоих случаях получены вполне приемлемые результаты теоретической оценки полных относительных деформаций. Схема 1 дает хорошее совпадение с опытом при продолжительности испытаний $t$ - $\tau=112$ суток, схема 2 дает лучшее совпадение при $t$ - $\tau>$ 112 суток.

Внутреннее напряженное состояние бетона по схеме 1 будет постоянным и определяется длительно приложенной сжимающей нагрузкой различной интенсивности.

При схеме 2 внутреннее напряженное состояние бетона - не постоянное, вследствие перераспределения усилий с цементного камня (раствора) на заполнитель. Численные значения напряжений в составляющих бетона для схемы 2, с учетом перераспределения усилий между ними для различных моментов времени $t-\tau$ и уровней обжатия $\eta \tau$, приведены в табл. 2. 
Опытные и теоретические относительные деформации $\varepsilon_{\eta, t, \tau} 10^{-5}$ системы «раствор-бетон», полученные по идеализированной структурной схеме 2 для серии ТБ-3 в процессе длительного сжатия различной интенсивности

\begin{tabular}{|c|c|c|c|c|c|c|c|c|}
\hline \multirow{3}{*}{$\begin{array}{c}\text { Сутки } \\
(t-\tau)\end{array}$} & $\begin{array}{l}\text { Способ } \\
\text { определения }\end{array}$ & \multicolumn{7}{|c|}{$\varepsilon_{\eta, t, \tau} \quad 10^{-5}$} \\
\hline & $\sigma$ МПа & 5 & 7,5 & 10,0 & 12,5 & 15,0 & 17,5 & 20,0 \\
\hline & $\eta_{\tau}$ & 0,2 & 0,3 & 0,4 & 0,5 & 0,6 & 0,7 & 0,8 \\
\hline \multirow{3}{*}{1} & опытный & 18,3 & 29,8 & 42,1 & 55,6 & 75,6 & 107,0 & 151,4 \\
\hline & теорет. & 15,3 & 24,4 & 34,9 & 47,4 & 63,3 & 84,7 & 116,6 \\
\hline & $\Delta \%$ & $-16,3$ & $-18,1$ & $-17,3$ & $-14,7$ & $-16,3$ & $-20,8$ & $-23,1$ \\
\hline \multirow{3}{*}{3} & опытный & 19,3 & 31,2 & 444,6 & 58,7 & 79,5 & 110,4 & 157,6 \\
\hline & теорет. & 16,2 & 26,0 & 37,4 & 51,5 & 69,7 & 95,3 & 136,0 \\
\hline & $\Delta \%$ & $-16,7$ & $-16,7$ & $-16,1$ & $-14,0$ & $-12,3$ & $-13,7$ & $-13,7$ \\
\hline \multirow{3}{*}{7} & опытный & 20,2 & 32,7 & 46,9 & 62,0 & 83,8 & 114,0 & 163,6 \\
\hline & теорет. & 17,3 & 27,8 & 40,1 & 55,2 & 74,8 & 102,3 & 145,7 \\
\hline & $\Delta \%$ & $-14,3$ & $-15,0$ & $-14,5$ & $-11,0$ & $-10,7$ & $-10,2$ & $-11,0$ \\
\hline \multirow{3}{*}{14} & опытный & 21,2 & 35,1 & 49,2 & 64,7 & 86,8 & 119,4 & 168,0 \\
\hline & теорет. & 18,1 & 29,2 & 42,5 & 59,2 & 81,5 & 114,4 & 170,7 \\
\hline & $\Delta \%$ & $-14,6$ & $-16,8$ & $-13,6$ & $-8,5$ & $-6,1$ & $-4,2$ & $+1,6$ \\
\hline \multirow{3}{*}{28} & опытный & 22,4 & 36,4 & 52,9 & 69,4 & 90,8 & 123,3 & 173,0 \\
\hline & теорет. & 19,1 & 30,8 & 44,8 & 62,4 & 85,9 & 120,1 & 177,4 \\
\hline & $\Delta \%$ & $-14,7$ & $-15,3$ & $-15,3$ & $-10,1$ & $-5,4$ & $-2,6$ & $+2,5$ \\
\hline \multirow{3}{*}{57} & опытный & 24,4 & 39,0 & 57,4 & 75,2 & 95,7 & 127,8 & 180,8 \\
\hline & теорет. & 21,2 & 34,2 & 49,6 & 68,8 & 93,7 & 128,5 & 182,7 \\
\hline & $\Delta \%$ & $-13,1$ & $-12,3$ & $-13,6$ & $-8,5$ & $-2,1$ & $+0,5$ & $+1,0$ \\
\hline \multirow{3}{*}{112} & опытный & 27,2 & 42,3 & 62,5 & 81,2 & 101,3 & 133,6 & 200,0 \\
\hline & теорет. & 22,9 & 37,4 & 55,4 & 78,9 & 111,8 & 163,3 & 260,3 \\
\hline & $\Delta \%$ & $-15,8$ & $-11,6$ & $-11,3$ & $-2,8$ & $+10,3$ & $+22,2$ & $+30,1$ \\
\hline \multirow{3}{*}{178} & опытный & 28,9 & 44,7 & 66,6 & 85,5 & 104,9 & 138,8 & 206,6 \\
\hline & теорет. & 25,1 & 41,0 & 60,7 & 86,3 & 121,8 & 176,3 & 274,3 \\
\hline & $\Delta \%$ & $-13,1$ & $-8,3$ & $-8,9$ & $+0,9$ & $+14,8$ & $+26,0$ & $+32,4$ \\
\hline \multirow{3}{*}{$\infty$} & опытный & 31,9 & 52,1 & 73,4 & 105,0 & 135,2 & 170,5 & 212,8 \\
\hline & теорет. & 29,9 & 48,9 & 72,2 & 102,1 & 142,6 & 202,1 & 300,2 \\
\hline & $\Delta \%$ & $-0,3$ & $-6,1$ & $-1,6$ & $-2,8$ & $+5,4$ & $+18,5$ & $+40,7$ \\
\hline
\end{tabular}

Таблица 2

Внутреннее напряженное состояние бетона в процессе длительного сжатия различной интенсивности в системе «раствор-бетон», полученное по идеализированной структурной схеме 2 , МПа

\begin{tabular}{|c|l|c|c|c|c|c|c|c|}
\hline \multirow{2}{*}{$\begin{array}{c}t \text { - } \tau \\
\text { суток }\end{array}$} & Напряже- & \multicolumn{7}{|c|}{$\eta_{\tau}=\sigma_{\tau} / f c d, \tau$} \\
\cline { 3 - 9 } & ние & 0,2 & 0,3 & 0,4 & 0,5 & 0,6 & 0,7 & 0,8 \\
\hline \multirow{2}{*}{1} & $\sigma_{I, \eta, t, \tau}$ & 2,1 & 3,1 & 4,1 & 5,0 & 5,8 & 6,7 & 7,5 \\
& $\sigma_{3, \eta, t, \tau}$ & 7,0 & 10,6 & 14,2 & 17,8 & 21,4 & 25,1 & 28,8 \\
\hline \multirow{2}{*}{28} & $\sigma_{l, \eta, t, \tau}$ & 1,7 & 2,4 & 3,2 & 3,9 & 4,7 & 5,4 & 6,1 \\
& $\sigma_{3, \eta, t, \tau}$ & 7,4 & 11,1 & 14,8 & 10,5 & 22,3 & 26,0 & 29,8 \\
\hline \multirow{2}{*}{178} & $\sigma_{I, \eta, t, \tau}$ & 1,2 & 1,8 & 2,4 & 2,9 & 3,5 & 4,1 & 4,7 \\
& $\sigma_{3, \eta, t, \tau}$ & 7,7 & 11,5 & 15,4 & 19,2 & 23,1 & 26,9 & 30,8 \\
\hline \multirow{2}{*}{$\infty$} & $\sigma_{I, \eta, t, \tau}$ & 1,0 & 1,5 & 1,9 & 2,4 & 2,9 & 3,4 & 3,7 \\
& $\sigma_{3, \eta, t, \tau}$ & 7,8 & 11,7 & 15,7 & 19,6 & 23,5 & 27,4 & 31,5 \\
\hline
\end{tabular}


Таблица 3

Опытные и теоретические относительные деформации $\varepsilon_{\eta, t, \tau} \mathbf{1 0}^{-5}$ системы «раствор-бетон», полученные по идеализированной структурной схеме 1 для серии ТБ-3 в процессе длительного сжатия различной интенсивности

\begin{tabular}{|c|c|c|c|c|c|c|c|c|}
\hline \multirow{3}{*}{$\begin{array}{c}\text { Сутки } \\
(t-\tau)\end{array}$} & $\begin{array}{l}\text { Способ } \\
\text { определения }\end{array}$ & \multicolumn{7}{|c|}{$\varepsilon_{\eta, t, \tau} \quad 10^{-5}$} \\
\hline & $\sigma \mathrm{M \Pi а}$ & 5 & 7,5 & 10,0 & 12,5 & 15,0 & 17,5 & 20,0 \\
\hline & $\eta_{\tau}$ & 0,2 & 0,3 & 0,4 & 0,5 & 0,6 & 0,7 & 0,8 \\
\hline \multirow{3}{*}{1} & опытный & 18,3 & 29,8 & 42,1 & 55,6 & 75,6 & 107,0 & 151,4 \\
\hline & теорет. & 17,8 & 28,5 & 41,0 & 55,6 & 73,2 & 95,0 & 122,7 \\
\hline & $\Delta \%$ & $-3,3$ & $-4,7$ & $-2,6$ & 0 & $-3,2$ & $-11,2$ & $-19,0$ \\
\hline \multirow{3}{*}{3} & опытный & 19,3 & 31,2 & 44,6 & 58,7 & 79,5 & 110,4 & 157,6 \\
\hline & теорет. & 19,1 & 30,8 & 44,4 & 60,7 & 80,3 & 105,0 & 137,1 \\
\hline & $\Delta \%$ & $-1,0$ & $-1,3$ & $-0,5$ & $+3,4$ & $+1,0$ & $-4,9$ & $-13,0$ \\
\hline \multirow{3}{*}{7} & опытный & 20,2 & 32,7 & 46,9 & 62,0 & 83,8 & 114,0 & 163,6 \\
\hline & теорет. & 20,7 & 33,2 & 48,0 & 65,4 & 86,6 & 113,0 & 147,0 \\
\hline & $\Delta \%$ & $+2,5$ & $+1,5$ & $+2,4$ & $+5,5$ & $+3,3$ & $-0,9$ & $-10,2$ \\
\hline \multirow{3}{*}{14} & опытный & 21,2 & 35,1 & 49,2 & 64,7 & 86,8 & 119,4 & 168,0 \\
\hline & теорет. & 21,8 & 35,2 & 51,0 & 70,0 & 93,4 & 123,2 & 162,4 \\
\hline & $\Delta \%$ & $+2,8$ & $+0,3$ & $+1,6$ & $+8,2$ & $+7,6$ & $+3,2$ & $-3,3$ \\
\hline \multirow{3}{*}{28} & опытный & 22,4 & 36,4 & 52,9 & 69,4 & 90,8 & 123,3 & 173,0 \\
\hline & теорет. & 23,2 & 37,4 & 54,2 & 74,3 & 98,9 & 129,8 & 170,4 \\
\hline & $\Delta \%$ & $+3,6$ & $+2,7$ & $+2,5$ & $+7,0$ & $+8,9$ & $+5,3$ & $-1,5$ \\
\hline \multirow{3}{*}{57} & опытный & 24,4 & 39,0 & 57,4 & 75,2 & 95,7 & 127,8 & 180,8 \\
\hline & теорет. & 26,3 & 42,4 & 61,0 & 83,0 & 109,5 & 142,2 & 183,7 \\
\hline & $\Delta \%$ & $+7,8$ & $+8,7$ & $+4,5$ & $+10,3$ & $+14,4$ & $+11,2$ & $+1,6$ \\
\hline \multirow{3}{*}{112} & опытный & 27,2 & 42,3 & 62,5 & 81,2 & 101,3 & 133,6 & 200,0 \\
\hline & теорет. & 28,8 & 46,7 & 68,1 & 94,0 & 126,3 & 167,8 & 223,4 \\
\hline & $\Delta \%$ & $+5,9$ & $+10,4$ & $+8,9$ & $+13,6$ & $+24,8$ & $+25,6$ & $+11,7$ \\
\hline \multirow{3}{*}{178} & опытный & 28,9 & 44,7 & 66,6 & 85,5 & 104,9 & 138,8 & 206,6 \\
\hline & теорет. & 32,0 & 51,8 & 75,4 & 103,7 & 138,7 & 183,2 & 241,9 \\
\hline & $\Delta \%$ & $+10,7$ & $+15,8$ & $+15,0$ & $+21,3$ & $+32,0$ & $+31,8$ & $+17,0$ \\
\hline \multirow{3}{*}{$\infty$} & опытный & 31,9 & 52,1 & 73,4 & 105,0 & 135,2 & 170,5 & 212,8 \\
\hline & теорет. & 39,1 & 63,2 & 91,4 & 124,9 & 165,6 & 216,1 & 280,8 \\
\hline & $\Delta \%$ & $+26,2$ & $+21,2$ & $+24,6$ & $+19,0$ & $+29,7$ & $+26,6$ & $+32,0$ \\
\hline
\end{tabular}

Выводы. Структурная теория сопротивления бетонов силовым воздействием базируется на идеализации их структурных схем. Наиболее полно отражает работу бетона при сжатии и растяжении идеализированная структурная схема в виде шахматного расположения кубических зерен заполнителя в растворной части бетона.

Принятая идеализированная структурная схема бетонов позволила оценить по заданному их составу и реологическим свойствам составляющих напряженно-деформированное состояние бетонов при длительном центральном сжатии (модуль упругости, секущий модуль деформаций и деформации ползучести).

Полученные и предлагаемые к практическому применению теоретические зависи- мости оценки напряженно-деформированного состояния бетонов при длительном приложении нагрузки с переменой знака усилий получили вполне удовлетворительное экспериментальное подтверждение.

Эти зависимости могут быть использованы при уточнении положений ДБН В.2.6.98:2009 «Бетонні та залізобетонні конструкції» при определении деформативных характеристик бетонов.

\section{Список литературы}

1. Ахвердов М. Н. Механизм усадки и ползучести бетона в свете современных представлений реологии и физики твердого тела. Бетон и железобетон. 1970. № 10. C. 21-23. 
2. Битько Н. М., Кузнецова О. В., Бойко В. В. Напряженно-деформированное состояние бетонов при кратковременном центральном сжатии, исходя из его идеализированных структурных схем. Вісник Черкаського державного технологічного університету. Серія: Технічні науки. 2016. № 3. С. 84-89.

3. Битько Н. М., Архангельская Н. А., Кузнецова О. В., Бойко В. В. Напряженнодеформированное состояние цементного камня при длительном центральном сжатии нагрузкой различной интенсивности. Вісник Черкаського державного технологічного університету. Серія: Технічні науки. 2009. № 2. C. 7-13.

4. Гансен Т. Ползучесть и релаксация напряжений в бетоне / пер. с англ. Москва: Госстройиздат, 1963. С. 124.

5. Гегасян С. Г. Собственные колебания вязкоупружной модели наследственного старения. Бетон и железобетон, 2001. № 5. C. 6-8.

6. Учет явления систематической неоднородности свойств тяжелого бетона. Безопасность эксплуатаиии зданий и сооружений: монография / Горохов Е. В., Югов А. М., Веретенников В. Н. и др. Москва, 2011. C. 146-167.

7. Дмитриев А. С. Влияние крупного заполнителя на прочность и деформативность высокопрочного бетона. Bопросы общей технологии и ускорение твердение бетона: сб. НИИЖБ / под ред. С. А. Миронова. Москва: Стройиздат, 1970. С. 58-63.

8. Зайцев Ю. В. Современное состояние механики бетона в России и за рубежом. Строительные материаль, оборудование, технологии XXI века. 2003. № 1. С. 18-19.

9. Крылов С. Б., Гончаров Е. Е. Использование реологических моделей при моделировании ползучести бетона. Промышленное $u$ гражданское строительство, 2013. № 2. C. 32-33.

10.Макаренко Л. П., Битько Н. М. Экспериментально-статистические исследования напряженно-деформированного состояния цементного камня и бетона при двух режимах центрального сжатия с постоянной скоростью роста загрузки и продольных деформаций. Вопросы надежности железобетонных конструкций: сб. / под ред. А. С. Лычева. Куйбышев, 1977. С. 89-92.

11.Макаренко Л. П., Битько Н. М. Экспериментально-статистические исследования зависимости напряжения деформаций в цементном камне и бетонах, при длительном центральном сжатии постоянной нагрузкой различной интенсивности. Вопроcbl надежности железобетонных конструкиий: сб. / под. ред. А. С. Лычова. Куйбышев, 1976. С. 106-109.

12.Макаренко Л. П., Фенко Г. А. В Влияние ползучести и усадки при длительном обжатии бетонов на их трещиностойкость и прочность при последующем растяжении. Ползучесть и усадка бетона: сб., подготовл. НИИСК Госстрой СССР (материалы совещания союзной комиссии РИЛЕМ), Киев: Будивельник, 1969.

13.Фенко Г. А. Влияние собственных напряжений на свойства бетона: дис. ... к.т.н. Полтава: Полтавский ИСИ, 1972.

\section{References}

1. Akhverdov, M. N. (1970) The mechanism of concrete shrinkage and creep in the light of current ideas on rheology and solid-state physics. Beton i zhelezobeton, (10), pp. 21-23 [in Russian].

2. Bitko, N. M., Kuznetsova, O. V., Boyko, V. V. (2016) Stress-strain state of concrete under short-term central compression, based on its idealized structural schemes. Visnyk Cherkaskogo derzhavnogo tehnologichnogo universitetu. Seria: Tehnichni nauky, No. 3, pp. 84-89 [in Russian].

3. Bitko, N. M., Arkhangelskaya, N. A., Kuznetsova, O. V., Boyko, V. V. (2009) Stressstrain state of cement stone with long-term central compression load of varying intensity. Visnyk Cherkaskogo derzhavnogo tehnologichnogo universitetu. Seria: Tehnichni nauky, No. 2, pp. 7-13 [in Russian].

4. Gansen, T. (1963) Creep and stress relaxation in concrete. Moscow: Gosstroyizdat, p. 124 [in Russian].

5. Gegasyan, S. G. (2001) Characteristic oscillations of viscous-elastic model of hereditary aging. Beton $i$ zhelezobeton, (5), pp. 6-8 [in Russian].

6. Gorokhov, Ye. V., Yugov, A. M., Veretennikov, V. N. et al. (2011) Accounting of the phenomenon of systematic heterogeneity of heavy concrete features. In: Bezopasnost ekspluatatsii zdaniy $i$ sooruzheniy. Moscow, pp. 146-167 [in Russian].

7. Dmitriyev, A. S. (1970) Coarse aggregate impact on the strength and stress-strain behavior of high-precision concrete. Voprosy obshchey 
tekhnologiyi $i$ uskoreniye tverdeniya betona: coll. NIIZhB, pod red. S. A. Mironova. Moscow: Stroyizdat, pp. 58-63 [in Russian].

8. Zaytsev, Yu. V. (2003) Current state of concrete mechanics in Russia and abroad. Stroyitel'nye materialy, oborudovaniye, tekh-nologiyi XXI veka, (1), pp. 18-19 [in Russian].

9. Krylov, S. B., Goncharov, Ye. Ye. (2013) The use of rheological models at concrete creep simulation. Promyshlennoye i grazhdanskoye stroyitel'stvo, (2), pp. 32-33 [in Russian].

10. Makarenko, L. P., Bitko, N. M. (1977) Experimental and statistic studies of deflected mode of cement stone and concrete at two modes of axial compression with constant speed of loading and longitudinal strain growth. Voprosy nadyezhnosti zhelezobeton-nykh konstruktsiy, pod. red. A. S. Lycheva. Kuybyshev, pp. 89-92 [in Russian].
11.Makarenko, L. P., Bitko, N. M. (1976) Experimental and statistic studies of the dependence of deformation strain in cement stone and concrete at sustained axial compression by constant loading of various intensity. $\mathrm{Vo}$ prosy nadyezhnosti zhelezobe-tonnykh konstruktsiy, pod. red. A. S. Lycheva. Kuybyshev, pp. 106-109 [in Russian].

12.Makarenko, L. P., Fenko, G. A. (1969) The effect of creep and shrinkage during prolonged compression of concrete on their crack resistance and strength during subsequent stretching. Polzuchest $i$ usadka betona: coll., prepared by NIISK Gosstroy of the USSR (materials of the meeting of the Allied Commission of RILEM), Kiev, Budivelnik [in Russian].

13.Fenko, G. A. (1972) Effect of intrinsic stresses on concrete properties: $\mathrm{PhD}$ thesis. Poltava: Poltava ISI [in Russian].

N. M. Bitko, Ph.D., associate professor,

e-mail: bitkonm@ukr.net

O. V. Kuznetsova, senior lecturer, e-mail: kuznes-68@ukr.net

V. V. Boiko, senior lecturer

e-mail: boykin.valentina@gmail.com

Cherkasy State Technological University

Shevchenko blvd, 460, Cherkasy, 18006, Ukraine

\section{THEORETICAL STUDIES OF STRESS-STRAIN STATE OF CONCRETE UNDER LONG-TERM CENTRAL COMPRESSION}

The results of theoretical studies of stress-strain state of concrete under long-term central compression based on its structural theory are presented. The analysis of determining the stress-strain state on the basis of two most acceptable structural diagrams of concrete is conducted. Positive and negative aspects of the use of these diagrams are given. Based on the analysis, two diagrams have been selected to determine elastoplastic characteristics of concrete under long-term loading based on rheological properties of components. For the diagram of chess spacing of the aggregate in cement matrix, based on equilibrium solutions and the compatibility of deformations, their theoretical values are obtained. Comparisons of the obtained theoretical values of the characteristics of concrete and mortar under a long-term load with the data obtained experimentally are conducted. The results of comparison of experimental and theoretical values indicate the possibility of applying these dependencies to determine elastoplastic characteristics of concrete under a long-term load based on the composition of its components.

Keywords: modulus of elasticity, concrete, mortar, structural diagram, components of concrete, aggregate, cement stone. 


\section{М. М. Битько, к.т.н., доцент, e-mail: bitkonm@ukr.net \\ О. В. Кузнецова, старший викладач, e-mail: kuznes-68@ukr.net \\ В. В. Бойко, стариий викладач \\ e-mail: boykin.valentina@gmail.com \\ Черкаський державний технологічний університет \\ б-р Шевченка, 460, м. Черкаси, 18006, Україна \\ ТЕОРЕТИЧНІ ДОСЛІДЖЕННЯ НАПРУЖЕНО-ДЕФОРМОВАНОГО СТАНУ БЕТОНІВ ПРИ ДОВГОТРИВАЛОМУ ЦЕНТРАЛЬНОМУ СТИСНЕННІ}

Бетон є основним будівельним матеріалом. Мічнісні й деформативні характеристики бетону залежать від його складових та їх взаєморозташування в одинииі елемента, яке здійснюється за допомогою ідеалізованих структурних схем бетону. Дійсна структурна схема бетону є складною і не піддається статистичному оцінюванню. Цементний камінь при цьому розглядається як матриия, а заповнювачі - як включення. Однак цементний камінь і заповнювач мають різні фізико-механічні властивості. Тому пружно-пластичні і міцнісні характеристики бетону повинні визначатися через аналітичні характеристики складових, їх кількісне співвідношення і взаєморозташування. Рішення такої задачі є досить актуальним.

Нині є незначна кількість робіт з иієї проблеми, що дають аналітичні залежності для визначення пружсооластичних характеристик бетону за ідеалізованими структурними схемами при короткочасному завантаженні. Щодо його оцінки при довготривалому стисненні навантаженням різної інтенсивності, то такі дані відсутні. Тому основна мета роботи полягає в розробиі аналітичних залежностей, на основі ідеалізованих структурних схем, для визначення його напружено-деформованого стану при довготривалому стисненні різної інтенсивності, виходячи з реологічних властивостей складових бетону.

Для вирішення поставленої задачі використано дві ідеалізовані структурні схеми, які найбільш точно відображають роботу бетону при стисненні.

Крім того, використано нелінійну залежність між напруженням і характеристикою повзучості $\varphi_{\eta, t . \tau}$ а також лінійну залежність між січним модулем повних деформацій (з урахуванням деформачій повзучості) $E_{\eta, t . \tau}^{\prime}$ і початковим рівнем довготривалих напружень $\eta_{\tau}$ у фіксований момент часу $(t-\tau)$ для цементного каменю (розчину). раніме.

Експериментально статистичне обтрунтування вищезазначеного отримано авторами

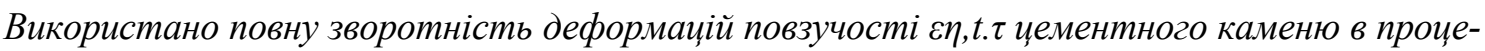
сі його розвантаження за рахунок перерозподілу зусиль між цементним каменем і заповнювачем.

На основі вищезазначеного із рівнянь рівноваги і сумісності деформацій отримано аналітичні залежності для визначення пружнопластичних характеристик бетону за ідеалізованими структурними схемами, виходячи з його складу і властивостей компонентів.

Наведено дослідні й теоретичні значення відносних деформачій, отриманих за однією з ідеалізованих структурних схем важкого бетону в прочесі довготривалою стиснення різної інтенсивності.

Отримані й запропоновані до практичного застосування теоретичні залежності оцінювання напружено-деформованого стану бетону при довготривалому стисненні різної інтенсивності за ідеалізованими структурними схемами, виходячи з їх складу та реологічних властивостей компонентів, мають задовільне експериментальне підтвердження.

Ці залежності можуть бути використані при уточненні положень ДБН В.2.6. - 98-2009 «Бетонні та залізобетонні конструкції» при визначенні деформативних характеристик бетонів.

Ключові слова: модуль пружності, бетон, розчин, структурна схема, складові бетону, заповнювач, иеементний камінь. 